\title{
Follow-up study of liver metastasis from breast cancer treated by proton beam therapy
}

\author{
NOBUYOSHI FUKUMITSU, TOSHIYUKI OKUMURA, HARUKO NUMAJIRI, \\ DAICHI TAKIZAWA, KAYOKO OHNISHI, MASASHI MIZUMOTO, TERUHITO AIHARA, \\ HITOSHI ISHIKAWA, KOJI TSUBOI and HIDEYUKI SAKURAI
}

Proton Medical Research Center, University of Tsukuba, Tsukuba, Ibaraki 305-8575, Japan

Received September 4, 2016; Accepted March 17, 2017

DOI: $10.3892 / \mathrm{mco} .2017 .1283$

\begin{abstract}
Liver metastasis from breast cancer (LMBC) is an incurable, fatal disease with a very poor prognosis. Although various local treatments have been applied, their clinical utility has not been established. The purpose of this study was to investigate the safety and effectiveness of proton beam therapy (PBT) for the treatment of patients with LMGC. A total of 8 female patients (aged 38-63 years) with LMBC who received PBT between 2002 and 2012 were retrospectively reviewed. Patients who had tumors confined to the liver were investigated, whereas patients with extrahepatic tumors were excluded. A total of 5 patients had solitary tumors and 3 had multiple tumors. The total irradiation dose was 66-72.6 Gray equivalent [Gy relative biological effectiveness (RBE)] and 2 patients received concurrent chemotherapy or hormone therapy. The overall and progression-free survival (OS and PFS) rates, local control (LC) rate and adverse effects were investigated. All the patients completed treatment without interruption and late adverse effects of grade $>3$ were not observed. The OS rate was $88 / 73 / 58 \%$, the PFS rate was $50 / 25 / 0 \%$ and the LC rate was $86 / 86 / 86 \%$ at $1 / 3 / 5$ years, respectively. Thus, PBT is a safe treatment and the OS and PFS rates are comparable to those with other local treatments. PBT may be considered as an effective local treatment option for the treatment of LMBC patients.
\end{abstract}

\section{Introduction}

Approximately 50\% of breast cancer patients will develop distant metastasis $(1,2)$, which is a major cause of cancer-related mortality among women (3). In most series, isolated liver metastases are found in 5-25\% of the cases $(1,2,4-6)$. As the majority of LMBC patients may have systemic disease, only a limited number of patients are candidates for local treatment.

Correspondence to: Dr Nobuyoshi Fukumitsu, Proton Medical Research Center, University of Tsukuba, 1-1-1 Tennoudai, Tsukuba, Ibaraki 305-8575, Japan

E-mail: fukumitsun@yahoo.co.jp

Key words: proton beam therapy, metastatic liver tumor, breast cancer, survival rate, local control rate
Although systemic chemotherapy regimens with new molecular-targeted agents have been developed, LMBC is an incurable, fatal disease, with a median survival of 3-15 months $(5,7,8)$ and the management of liver metastases remains challenging. Thus, the treatment of patients with LMBC is considered as palliative. To improve the treatment outcome, various local treatments, such as surgery and transcatheter arterial chemoembolization (TACE) have been applied, in combination with chemotherapy or performed alternatively. However, the clinical utility of local treatment has not been established in LMBC; by contrast, surgery is widely considered to be a useful treatment option in liver metastasis from colorectal cancer (9).

Proton beam therapy (PBT) is characterized by precisely delivering a high dose of radiation to the target, while significantly limiting the exposure of regions beyond the target. It is well known that PBT for primary liver cancer achieves excellent local control rates with few adverse effects (10-14). The preliminary outcome of 5 LMBC cases who received PBT during a maximum follow-up period of 8 years in 2012 was previously reported (15). The cases were further followed up and new patients with LMBC who were treated using PBT were included in order to investigate the safety and effectiveness of PBT for LMBC patients.

\section{Patients and methods}

Patients. A total of 8 patients with LMBC who received PBT at the University of Tsukuba (Tsukuba, Japan) between 2003 and 2013 were retrospectively investigated. All the patients were women and had a median age of 47 years (range, 38-63 years). The tumors were categorized as solitary or multiple tumors that could be included within a few irradiation fields. Patients with extrahepatic tumors were excluded.

The time interval from primary disease surgery to PBT was 3-14 years (median, 5 years) in 7 patients with metachronous metastasis and the surgery was performed after PBT in the remaining patient who had synchronous metastasis. Of the 8 patients, 5 had solitary tumors and 3 had multiple tumors. The tumor distribution was unilateral in all cases. The maximal diameter of the tumors was $1.2-7 \mathrm{~cm}$ (median, $4 \mathrm{~cm}$ ). All the patients had received another form of treatment prior to PBT, such as chemotherapy and/or hormone therapy. 
Two patients received concurrent chemotherapy and hormone therapy. According to the Eastern Cooperative Oncology Group Performance Status (PS) scale, all the patients had a PS of 0-1 and a Child-Pugh score of 5 (class A). The follow-up period after PBT was 1.1-12.5 years (median, 3.8 years). The treatment strategy was discussed with surgeons on an individual basis, considering the patient's PS, tumor location and tumor size, and was approved in an in-hospital conference. The reason for selecting PBT was disease incurable by chemotherapy, surgery or radiofrequency ablation (RFA) in 7 cases and on the patient's request in 1 case. Written informed consent was obtained from all patients prior to PBT. The characteristics of the patients and tumors are summarized in Table I.

PBT. Computed tomography (CT) images were captured at 5 -mm intervals during the expiratory phase under a respiratory gating system (16). At the treatment planning stage, an aperture margin of 5-10 $\mathrm{mm}$, a depth margin of 5-10 $\mathrm{mm}$, and a 5-mm margin on the caudal axis were added to cover the entire clinical target volume to compensate for uncertainty resulting from respiration-induced hepatic movements. These margins included the field margins. A bolus was fabricated for the smearing process. Proton beams of 155-250 MeV, generated through a linear accelerator and synchrotron, were spread out and shaped with ridge filters, double-scattering sheets, multicollimators and custom-made boluses to ensure that the beams conformed to the treatment planning data. The patient's position was registered using an implanted fiducial marker and orthogonal fluoroscopy unit attached to the treatment unit. PBT was performed using a respiratory gating system (16).

The proton beam schedule was selected according to the tumor location and treatment strategy. Multiple tumors were included in the same irradiation field. The total irradiation dose was 66 Gray equivalent [Gy relative biological effectiveness (RBE)] in 22 fractions in 5 patients, and 72.6 Gy (RBE) in 22 fractions in 4 patients. The maximum cumulative dose was set for the spinal cord, stomach and duodenum to $<50 \mathrm{~Gy}$ (RBE), and for the colon to $<60 \mathrm{~Gy}(\mathrm{RBE})$. The RBE of the PBT was considered to be 1.1 (17).

Treatment after PBT. A total of 4 patients received adjuvant chemotherapy or hormone therapy following PBT. Moreover, a total of 5 patients received additional treatment to the new or recurrent tumors (PBT, X-ray radiotherapy, chemotherapy and/or hormone therapy).

Follow-up and evaluation criteria. During the treatment sessions, acute treatment-related toxicities were assessed weekly in all patients. After completion of PBT, the patients were evaluated by means of physical examinations, blood tests, and CT or MRI scans. Assessment of response was evaluated according to the Response Evaluation Criteria in Solid Tumors, version 1.1 (18). Local failure was defined as an increase in the maximal diameter of the treated target tumors of $>20 \%$ and $5 \mathrm{~mm}$. Adverse events were assessed after every procedure according to the Common Terminology Criteria for Adverse Effects (CTCAE), version 4.0 (19). Patients treated prior to 2010 were also retrospectively reviewed using the CTCAE 4.0
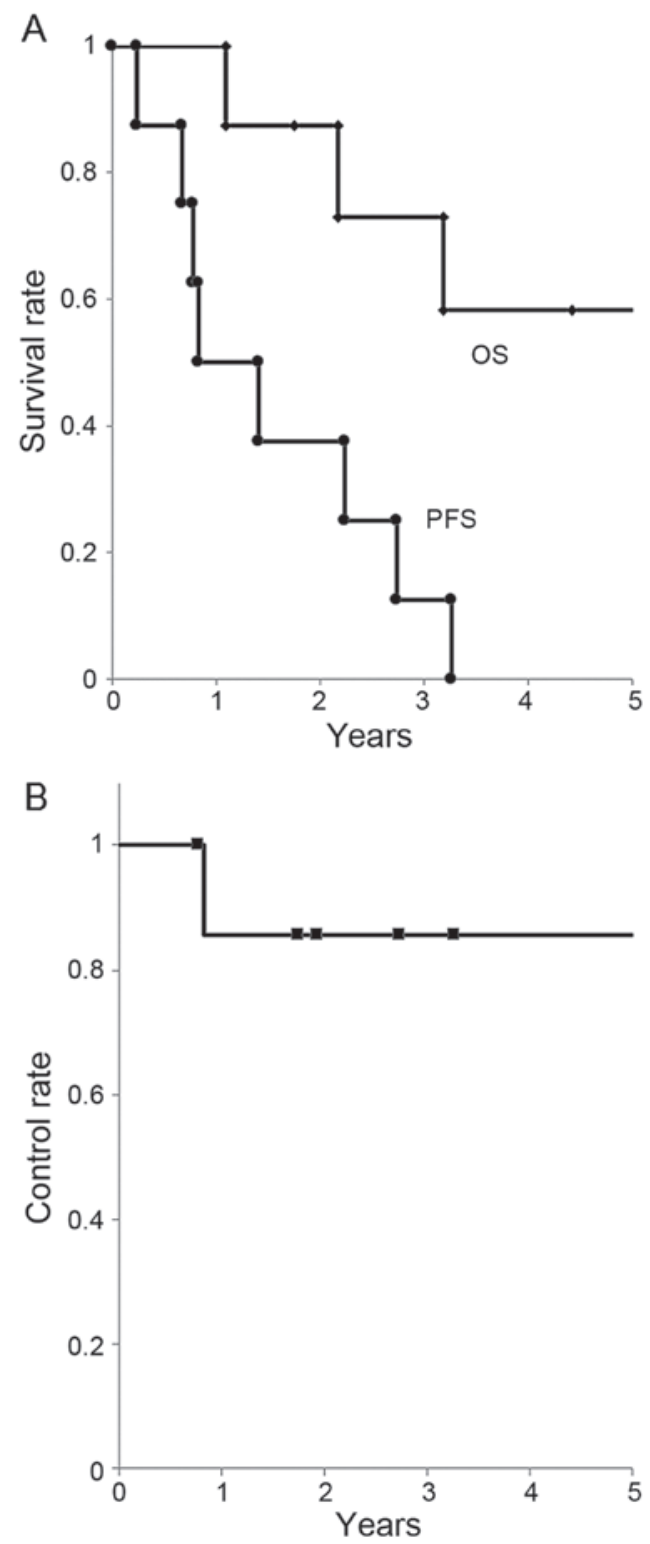

Figure 1. (A) Overall survival (OS) and progression-free survival (PFS) rates for all patients. (B) Local control rate for all patients

To determine safety, the treatment completion rate, liver toxicity and late adverse effects were examined. To assess the treatment effect, the OS, PFS and LC rates were calculated using the Kaplan-Meier method.

\section{Results}

Treatment dose. All the patients completed treatment without interruptions. The biologically effective dose for the liver $(\alpha / \beta=3)$ was 11.3-31.1 Gy (RBE) [median, 18.5 Gy (RBE)], and the volume that received $>30 \mathrm{~Gy}(\mathrm{RBE})\left(\mathrm{V}_{30}\right)$ was $12-39 \%$ (median, 23\%) of the liver. A late grade 2 adverse effect was observed in 1 patient (rib fracture 7 months after PBT).

Follow-up. A total of 5 patients remained alive at the final follow-up between July 2015 and March 2016, whereas 3 patients had succumbed to the disease. The follow-up period was 1.1-12.5 years (median, 3.8 years). The OS rate 
Table I. Summary of patient characteristics.

\begin{tabular}{|c|c|c|c|c|c|c|c|c|}
\hline Case & $\begin{array}{c}\text { Age, } \\
\text { years/gender }\end{array}$ & Number & Size, $\mathrm{cm}$ & $\begin{array}{l}\text { Dose, Gy } \\
(\mathrm{RBE}) / \mathrm{fr}\end{array}$ & $\begin{array}{l}\text { Previous } \\
\text { therapy }\end{array}$ & $\begin{array}{l}\text { Concurrent } \\
\text { therapy }\end{array}$ & $\begin{array}{l}\text { Adjuvant } \\
\text { therapy }\end{array}$ & $\begin{array}{c}\text { Survival } \\
\text { period, years }\end{array}$ \\
\hline 1 & $48 / \mathrm{F}$ & $\mathrm{S}$ & 2 & $66 / 10$ & $\mathrm{C}, \mathrm{H}$ & $\mathrm{N}$ & $\mathrm{N}$ & $12.5^{\mathrm{a}}$ \\
\hline 2 & $39 / \mathrm{F}$ & $\mathrm{S}$ & 7 & $66 / 10$ & $\mathrm{C}, \mathrm{H}$ & $\mathrm{N}$ & $\mathrm{N}$ & $8.9^{\mathrm{a}}$ \\
\hline 3 & $38 / \mathrm{F}$ & M & 4 & $66 / 10$ & $\mathrm{C}$ & $\mathrm{N}$ & $\mathrm{N}$ & $7.8^{\mathrm{a}}$ \\
\hline 4 & $63 / \mathrm{F}$ & $\mathrm{S}$ & 2.5 & $66 / 10$ & $\mathrm{C}, \mathrm{H}$ & $\mathrm{N}$ & $\mathrm{N}$ & $4.4^{\mathrm{a}}$ \\
\hline 5 & $51 / \mathrm{F}$ & $\mathrm{S}$ & 4 & $72.6 / 22$ & $\mathrm{C}$ & $\mathrm{N}$ & $\mathrm{N}$ & $3.2^{\mathrm{a}}$ \\
\hline 6 & $46 / F$ & M & 1.2 & $72.6 / 22$ & $\mathrm{C}$ & $\mathrm{N}$ & $\mathrm{N}$ & 2.2 \\
\hline 7 & $51 / \mathrm{F}$ & $\mathrm{S}$ & 4 & $72.6 / 22$ & $\mathrm{R}, \mathrm{H}$ & $\mathrm{H}$ & $\mathrm{H}$ & $1.8^{\mathrm{a}}$ \\
\hline 8 & $32 / \mathrm{F}$ & M & 5.5 & $72.6 / 22$ & $\mathrm{C}, \mathrm{H}$ & $\mathrm{C}$ & $\mathrm{C}$ & 1.1 \\
\hline
\end{tabular}

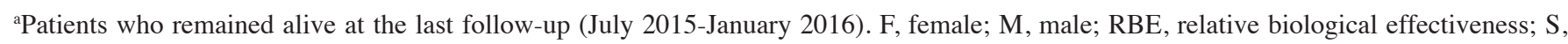
solitary; M, multiple; C, chemotherapy; H, hormone therapy; R, radiofrequent ablation; N, none.

Table II. Local treatment outcome of liver metastasis from breast cancer (review and present study).

\begin{tabular}{|c|c|c|c|c|c|c|c|c|}
\hline $\begin{array}{l}\text { First } \\
\text { author }\end{array}$ & $\begin{array}{c}\text { Patient } \\
\text { population, } \\
\mathrm{n}\end{array}$ & $\begin{array}{c}\text { Number } \\
(\mathrm{S} / \mathrm{M})\end{array}$ & $\begin{array}{c}\text { Distribution } \\
\text { (unilateral/ } \\
\text { bilateral) }\end{array}$ & $\begin{array}{c}\text { Size, } \mathrm{cm} \\
\text { (cut-off value, } \\
\text { patient no.) }\end{array}$ & Treatment & $\begin{array}{c}\text { 1/3/5-year } \\
\text { OS rate, } \% \\
\text { (median, years) }\end{array}$ & $\begin{array}{c}\text { 1/3/5-year } \\
\text { PFS rate, } \% \\
\text { (median, years) }\end{array}$ & (Refs.) \\
\hline Hoffmann & 29 & & & & SU & $-/ 75 / 59$ & & (21) \\
\hline Adam & 85 & $32 / 53$ & $52 / 33$ & $<5 / \geq 5,71 / 14$ & SU & $-/-/ 41(3.8)$ & $-/-/ 17$ & (20) \\
\hline Vlastos & 31 & $20 / 11$ & & $<2 / \geq 2,11 / 20$ & SU & $-/-/ 61(5.3)$ & $-/-/ 31$ & (22) \\
\hline Abbott & 86 & $53 / 33$ & & $<5 / \geq 5,73 / 13$ & SU & (4.8) & $(1.2)$ & (23) \\
\hline Pocard & 52 & $36 / 16$ & $28 / 24$ & $<3 / \geq 3,9 / 12$ & SU & $86 / 49 /-$ & & (24) \\
\hline $\mathrm{Li}$ & 29 & & & & TACE & 63/13/- & & (27) \\
\hline Vogl & 159 & & & & TACE & 64/36/- & & (26) \\
\hline Duan & 44 & & & & $\mathrm{TACE}+\mathrm{C}$ & $76 / 48 /-(2.6)$ & & (25) \\
\hline Present study & 8 & $5 / 3$ & $8 / 0$ & $<5 / \geq 5,5 / 2$ & PBT & $88 / 73 / 58$ & $50 / 25 / 0(0.8)$ & \\
\hline
\end{tabular}

S, solitary; M, multiple; OS, overall survival; PFS, progressionfree survival; SU, surgery; C, chemotherapy; TACE, transcatheter arterial chemoembolization; PBT, proton beam therapy.

was $88 / 73 / 58 \%$ at $1 / 3 / 5$ years, respectively. The PFS rate was $50 / 25 / 0 \%$ at $1 / 3 / 5$ years, respectively (median, 0.8 years). The LC rate was $86 / 86 / 86 \%$ at $1 / 3 / 5$ years, respectively (Fig. 1).

Fig. 2 shows a 39-years-old woman with LMBC. The patient had a 7-cm solitary tumor in the right lobe of the liver that had not been controlled by chemotherapy. PBT was administered at a dose of $66 \mathrm{~Gy}$ (RBE) in 10 fractions. Due to the superior physical characteristic of proton beams, the tumor was conformally irradiated with high doses, while the left lobe of the liver and digestive organs received extremely low doses. No radiation-induced liver damage or gastrointestinal disorders were observed. Additional chemotherapy and PBT were performed to the new lesions after the initial PBT and the patient remains alive 8.9 years after PBT (last follow-up, December, 2015).

\section{Discussion}

Reports on the local treatment of the patients with LMBC are extremely rare. With surgery, the OS rate is $49-75 / 41-61 \%$ at $3 / 5$ years, respectively, with a median of 3.8-5.3 years (20-24).

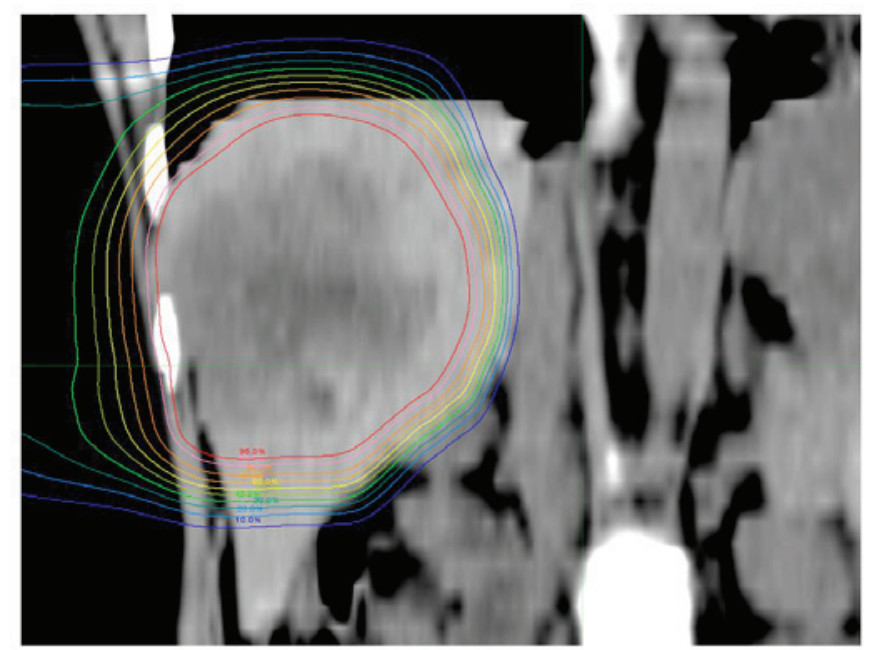

Figure 2. Dose distribution image (coronal plane) in a 39-year-old woman with liver metastasis from breast cancer. A sizeable $(7 \mathrm{~cm})$ tumor was identified in the right lobe and was treated with proton beam therapy at a dose of 66 Gy (relative biological effectiveness)/10 fractions. Isodose lines represent $95-10 \%$ from the center to the periphery. 
With TACE, the OS rate was $63-76 / 13-48 \%$ at $1 / 3$ years, respectively (25-27) (Table II). Although severe adverse effects are rare, Caralt et al reported that $2 / 12$ patients (17\%) suffered from bile leakage postoperatively (28).

The OS rate in our study was $88 / 73 / 58 \%$ at $1 / 3 / 5$ years, respectively, using PBT. Compared with the previous studies on local treatment, the number and size of the tumors did not differ significantly. However, our data on OS are consistent with that of the surgery, which is associated with the highest OS rate among optional treatments. As treatment of patients with LMBC is not satisfactory and the survival period with chemotherapy is 3-15 months, PBT may be a useful treatment option if the metastasis is confined to the liver. Moreover, although 1 patient suffered a late grade 2 adverse effect (rib fracture), there were no reported adverse event-related deaths, and no patients required hospitalization. Thus, PBT appears to be a safe treatment for $\mathrm{LMBC}$ patients.

The advantages of PBT for LMBC are considered to be as follows: i) Few adverse effects, ii) high local control rate, iii) treatment repeatability and iv) applicable to large tumors. First, tolerable doses to the liver have been well-documented. Austin-Seymour et al reported the tolerance dose as 30-35 Gy to one-third of the liver volume (29), and Emami et al reported a 5\% risk of liver dysfunction 5 years after radiotherapy with 30 Gy (30). The $V_{30}$ was $15-39 \%$ in our patients. It is well established that PBT for the treatment of primary liver cancers has the distinct advantage of causing relatively little damage to the healthy liver tissue $(10,12,31,32)$. The complications of hepatitis or liver cirrhosis are clearly less frequent in breast cancer patients compared with primary liver cancer patients. No patients exhibited a Child-Pugh score elevation of $>2$ during the follow-up in the present study. Based on safety data of previous studies on primary liver cancers, we consider the extent of liver toxicity to be very limited during treatment of $\operatorname{LMBC}(10,12,31,32)$. Second, it was previously reported that the $\mathrm{LC}$ rate is $98 / 87 / 81 \%$ at $1 / 3 / 5$ years, respectively, with PBT for primary liver cancers (11). It appears that the LC rate of LMBC is equal to that of primary liver cancers, possibly due to the fact that breast cancer is as radiosensitive as primary liver cancer. We consider that PBT may be applied as local treatment based on its high local control rate, particularly when other treatments have not proven to be useful. Third, breast cancer may cause additional metastatic tumors, some of which may appear in the liver. It is highly possible that additional local treatment is required for the new metastatic tumors in breast cancer patients. In the present study, 1 patient received additional PBT when new liver metastases appeared. Repeated PBT is occasionally applied for primary liver cancers and its safety has been proven (33). The most important factor for repeat PBT is liver function. Surgery is one of the standard options in local treatment. However, repeat surgery is not only difficult due to adhesions or complications, but is also associated with unacceptable risk in several patients. Considering the efficacy of repeated treatment for primary liver cancers and the lower frequency of complicated liver disease mentioned above, PBT is a safe and effective option for repeated treatment. Fourth, RFA, which is also one of the viable local treatment options in the view of its safety and repeatability, is limited to tumors sized $<5 \mathrm{~cm}$. PBT may be applied to treat significantly larger tumors without severe adverse effects. In the present study, 2 patients had tumors sized $>5 \mathrm{~cm}$. The patient with the largest tumor $(7 \mathrm{~cm})$ has received additional chemotherapy and radiotherapy and remains alive 8.8 years after treatment (last follow-up, December, 2015).

For patients with LMBC, chemotherapy is the first choice of treatment; however, the treatment outcome is not satisfactory. If the metastatic tumors are confined to the liver, several optional treatments have been attempted, some of which may achieve higher OS rates compared with conventional chemotherapy, although there are currently no available evidence-rich data. Our study was retrospective, and the number of patients was limited. However, to the best of our knowledge, only one case report of LMBC using PBT has been published to date (15), and ours is the first study to investigate survival rate from several patients. The OS rate was definitely not inferior to that of other local treatments, $(10-14,31,34)$. We consider that PBT was sufficiently effective to be considered as a viable local treatment option. Further investigation, with a larger patient sample is expected to provide more detailed information on the treatment of LMBC patients using PBT.

\section{Acknowledgements}

The present study was partially supported by Grants-in-Aid for Scientific Research (17H04256) in Japan.

\section{References}

1. Hoe AL, Royle GT and Taylor I: Breast liver metastases-incidence, diagnosis and outcome. J R Soc Med 84: 714-716, 1991.

2. Zinser JW, Hortobagyi GN, Buzdar AU, Smith TL and Fraschini G: Clinical course of breast cancer patients with liver metastases. J Clin Oncol 5: 773-782, 1987.

3. Jemal A, Murray T, Ward E, Samuels A, Tiwari RC, Ghafoor A, Feuer EJ and Thun MJ: Cancer statistics, 2005. CA Cancer J Clin 55: 10-30, 2005.

4. Inoue K, Ogawa M, Horikoshi N, Aiba K, Mukaiyama T, Mizunuma N, Itami S, Hirano A, Matsuoka A and Matsumura T: Evaluation of prognostic factors for 233 patients with recurrent advanced breast cancer. Jpn J Clin Oncol 21: 334-339, 1991.

5. O'Reilly SM, Richards MA and Rubens RD: Liver metastases from breast cancer: The relationship between clinical, biochemical and pathological features and survival. Eur J Cancer 26: 574-577, 1990.

6. Insa A, Lluch A, Prosper F, Marugan I, Martinez-Agullo A and Garcia-Conde J: Prognostic factors predicting survival from first recurrence in patients with metastatic breast cancer: Analysis of 439 patients. Breast Cancer Res Treat 56: 67-78, 1999.

7. Goldhirsch A, Gelber RD and Castiglione M: Relapse of breast cancer after adjuvant treatment in premenopausal and perimenopausal women: Patterns and prognoses. J Clin Oncol 6: 89-97, 1988.

8. Wyld L, Gutteridge E, Pinder SE, James JJ, Chan SY, Cheung KL, Robertson JF and Evans AJ: Prognostic factors for patients with hepatic metastases from breast cancer. Br J Cancer 89: 284-290, 2003.

9. Folprecht G, Gruenberger T, Bechstein W, Raab HR, Weitz J, Lordick F, Hartmann JT, Stoehlmacher-Williams J, Lang H and Trarbach T, et al: Survival of patients with initially unresectable colorectal liver metastases treated with FOLFOX/cetuximab or FOLFIRI/cetuximab in a multidisciplinary concept (CELIM study). Ann Oncol 25: 1018-1025, 2014.

10. Fukumitsu N, Sugahara S, Nakayama H, Fukuda K, Mizumoto M, Abei M, Shoda J, Thono E, Tsuboi K and Tokuuye K: A prospective study of hypofractionated proton beam therapy for patients with hepatocellular carcinoma. Int J Radiat Oncol Biol Phys 74: 831-836, 2009.

11. Mizumoto M, Okumura T, Hashimoto T, Fukuda K, Oshiro Y, Fukumitsu N, Abei M, Kawaguchi A, Hayashi Y, Ookawa A, et al: Proton beam therapy for hepatocellular carcinoma: A comparison of three treatment protocols. Int J Radiat Oncol Biol Phys 81: 1039-1045, 2011 
12. Bush DA, Hillebrand DJ, Slater JM and Slater JD: High-dose proton beam radiotherapy of hepatocellular carcinoma: Preliminary results of a phase II trial. Gastroenterology 127 (5 Suppl 1): S189-S193, 2004.

13. Kawashima M, Furuse J, Nishio T, Konishi M, Ishii H Kinoshita T, Nagase M, Nihei K and Ogino T: Phase II study of radiotherapy employing proton beam for hepatocellular carcinoma. J Clin Oncol 23: 1839-1846, 2005.

14. Qi WX, Fu S, Zhang Q and Guo XM: Charged particle therapy versus photon therapy for patients with hepatocellular carcinoma: A systematic review and meta-analysis. Radiother Oncol 114: 289-295, 2015.

15. Kanemoto A, Ishikawa $H$, Mizumoto $M$, Okumura $T$, Hashimoto T, Oshiro Y, Fukumitsu N, Tsuboi K, Sakae T and Sakurai H: Proton beam therapy for liver metastasis from breast cancer: Five case reports and a review of the literature. Int Canc Conf J 1: 210-214, 2012.

16. Fukumitsu N, Hashimoto T, Okumura T, Mizumoto M, Tohno E, Fukuda K, Abei M, Sakae T and Sakurai H: Investigation of the geometric accuracy of proton beam irradiation in the liver. Int J Radiat Oncol Biol Phys 82: 826-833, 2012.

17. Paganetti H, Niemierko A, Ancukiewicz M, Gerweck LE, Goitein M, Loeffler JS and Suit HD: Relative biological effectiveness (RBE) values for proton beam therapy. Int $\mathbf{J}$ Radiat Oncol Biol Phys 53: 407-421, 2002.

18. Eisenhauer EA, Therasse P, Bogaerts J, Schwartz LH, Sargent D, Ford R, Dancey J, Arbuck S, Gwyther S, Mooney M, et al: New response evaluation criteria in solid tumours: Revised RECIST guideline (version 1.1). Eur J Cancer 45: 228-247, 2009.

19. National Cancer Institute: Common terminology criteria for adverse events (CTCAE). https://ctep.cancer.gov/protocoldevelopment/electronic_applications/ctc.htm. Accessed May 28, 2009.

20. Adam R, Aloia T, Krissat J, Bralet MP, Paule B, Giacchetti S, Delvart V, Azoulay D, Bismuth H and Castaing D: Is liver resection justified for patients with hepatic metastases from breast cancer? Ann Surg 244: 897-908, 2006.

21. Hoffmann K, Franz C, Hinz U, Schirmacher P, Herfarth C, Eichbaum M, Büchler MW and Schemmer P: Liver resection for multimodal treatment of breast cancer metastases: Identification of prognostic factors. Ann Surg Oncol 17: 1546-1554, 2010.

22. Vlastos G, Smith DL, Singletary SE, Mirza NQ, Tuttle TM, Popat RJ, Curley SA, Ellis LM, Roh MS and Vauthey JN: Long-term survival after an aggressive surgical approach in patients with breast cancer hepatic metastases. Ann Surg Oncol 11: 869-874, 2004

23. Abbott DE, Brouquet A, Mittendorf EA, Andreou A, Meric-Bernstam F, Valero V, Green MC, Kuerer HM, Curley SA, Abdalla EK, et al: Resection of liver metastases from breast cancer: Estrogen receptor status and response to chemotherapy before metastasectomy define outcome. Surgery 151: 710-716, 2012.

24. Pocard M, Pouillart P, Asselain B and Salmon R: Hepatic resection in metastatic breast cancer: Results and prognostic factors Eur J Surg Oncol 26: 155-159, 2000.
25. Duan XF, Dong NN, Zhang T and Li Q: Treatment outcome of patients with liver-only metastases from breast cancer after mastectomy: A retrospective analysis. J Cancer Res Clin Oncol 137: 1363-1370, 2011.

26. Vogl TJ, Naguib NN, Nour-Eldin NE, Eichler K, Zangos S and Gruber-Rouh T: Transarterial chemoembolization (TACE) with mitomycin $\mathrm{C}$ and gemcitabine for liver metastases in breast cancer. Eur Radiol 20: 173-180, 2010.

27. Li XP, Meng ZQ, Guo WJ and Li J: Treatment for liver metastases from breast cancer: Results and prognostic factors. World J Gastroenterol 11: 3782-3787, 2005.

28. Caralt M, Bilbao I, Cortés J, Escartín A, Lázaro JL, Dopazo C, Olsina JJ, Balsells J and Charco R: Hepatic resection for liver metastases as part of the 'oncosurgical' treatment of metastatic breast cancer. Ann Surg Oncol 15: 2804-2810, 2008.

29. Austin-Seymour MM, Chen GT, Castro JR, Saunders WM, Pitluck S, Woodruff KH and Kessler M: Dose volume histogram analysis of liver radiation tolerance. Int $\mathrm{J}$ Radiat Oncol Biol Phys 12: 31-35, 1986.

30. Emami B,Lyman J, Brown A, Coia L, Goitein M, Munzenrider JE, Shank B, Solin LJ and Wesson M: Tolerance of normal tissue to therapeutic irradiation. Int J Radiat Oncol Biol Phys 21: 109-122, 1991.

31. Mizumoto M, Tokuuye K, Sugahara S, NakayamaH, Fukumitsu N, Ohara K, Abei M, Shoda J, Tohno E and Minami M: Proton beam therapy for hepatocellular carcinoma adjacent to the porta hepatis. Int J Radiat Oncol Biol Phys 71: 462-467, 2008.

32. Mizumoto M, Okumura T, Hashimoto T, Fukuda $K$, Oshiro Y, Fukumitsu N, Abei M, Kawaguchi A, Hayashi Y, Ohkawa A, et al: Evaluation of liver function after proton beam therapy for hepatocellular carcinoma. Int J Radiat Oncol Biol Phys 82: e529-e 535, 2012.

33. Hashimoto T, Tokuuye K, Fukumitsu N, Igaki H, Hata M, Kagei K, Sugahara S, Ohara K, Matsuzaki Y and Akine Y: Repeated proton beam therapy for hepatocellular carcinoma. Int J Radiat Oncol Biol Phys 65: 196-202, 2006.

34. Fukumitsu N, Okumura T, Takizawa D, Makishima H, Numajiri H, Murofushi K, Ohnishi K, Mizumoto M, Aihara T, Ishikawa $\mathrm{H}$, et al: Proton beam therapy for metastatic liver tumors. Radiother Oncol 117: 322-327, 2015. 